\title{
Tendencias actuales de la investigación genómica. Sus perspectivas en Nicaragua. ${ }^{1}$
}

Jorge A. Huete-Pérez

Centro de Biología Molecular, Universidad Centroamericana, miembro de la Academia de Ciencias de Nicaragua

En esta conferencia me enfoco en las tendencias y el impacto de las nuevas ciencias moleculares, cuyas revelaciones están transformando el mundo e incluso heredándonos una nueva cosmovisión. A continuación, consideraré las posibilidades de que un país pequeño como Nicaragua pueda contribuir en estas tendencias.

\section{Teoría de Darwin: origen y diversidad}

Al hablar sobre estos temas es inevitable hacer memoria de uno de los grandes hitos -quizás el más trascendental- de la historia de las ciencias biológicas, la formulación del concepto de evolución hace 150 años por el naturalista inglés Charles Darwin, fundamento indiscutible de la revolución genómica de nuestros días.

Una de las grandes bellezas de la teoría darwiniana de la evolución es que, al describir un mecanismo claro del origen de la diversidad biológica, le asigna a nuestra especie una ascendencia, su gran familia biológica, un origen compartido con todas las especies del planeta.

El conocimiento adquirido en la pesquisa del genoma humano, que ha ido dilucidándose a niveles de resolución cada vez más asombrosos, puso al descubierto la admirable naturaleza de la diversidad genética. Esa diversidad está presente no solamente entre grupos étnicos sino incluso entre individuos de una misma especie, algo que tiene que ser admitido abiertamente y, además, celebrado por su simbolismo estético y filosófico.

\section{El genoma humano}

El desciframiento del genoma humano, anunciado en 2001 y finalizado en 2003, realizado a través de un consorcio público internacional y por Celera Genomics, una compañía privada liderada por Craig Venter, es quizás el acontecimiento científico más sobresaliente de los últimos años. El genoma comprende el total de la información genética de una especie dada. Puede pensarse como un almacén de claves para la diferenciación celular que da paso a la conformación de tejidos y órganos de un individuo. 
Se consiguió determinar la secuencia de los 3 mil millones de pares de base e identificar los cerca de 25 mil genes que conforman el genoma humano. Se estima que cada gen podría codificar no solamente una proteína determinada -como se pensaba anteriormente- sino hasta diez proteínas distintas, con lo cual existirían unas 250 mil proteínas humanas. Si entendiéramos a los genes como códigos u ordenanzas, las proteínas serían las maquinarias celulares encargadas de ejecutarlas. Contaríamos con 250 mil dispositivos distintos involucrados cada uno en diversos procesos biológicos como la respiración celular, el desarrollo y la transmisión de señales.

Los cromosomas más densos, ricos en cuanto a contenido de genes, resultaron ser el 17, 19 y 22, que alojan a los genes responsables de enfermedades como el cáncer de mama, retinitis pigmentaria y neurofibromatosis tipo II. Los cromosomas más pobres, en cambio, resultaron ser el 4,12,18, asociados respectivamente a la narcolepsia, síndrome de Zellweger y Alzheimer. Considerado el cromosoma de la masculinidad, el cromosoma Y es el más pequeñito de todos, casi 10 veces menor que el cromosoma $X$, valorado como el cromosoma femenino. El cromosoma Y contiene poca información, mucha de ella repetitiva y -para colmo- aloja muchos genes involucrados en enfermedades. No todo es oscuro, sin embargo, ya que la indagación del contenido del cromosoma Y podría revelar explicaciones sobre las diferencias que presentan hombres y mujeres en cuanto a susceptibilidad a enfermedades.

\section{Genómica comparativa}

Una de las derivaciones de la genómica, la genómica comparativa, trata de identificar las diferencias entre especies cercanas. A partir de esas comparaciones hemos reconocido la extraordinaria proximidad entre humanos y primates. Se ha estimado que genéticamente el humano se asemeja al chimpancé en un 98\%. Estas comparaciones, que a algunos les parecerán indignantes, son importantes al menos para indagar los requisitos genéticos que diferencian a la especie humana del resto. En particular, la comprensión de las diferencias genéticas vierten luz sobre los procesos de evolución como la bifurcación con el chimpancé ocurrida hace 5-6 millones de años o la expansión geográfica del Homo sapiens (la salida de África) de hace 150 mil y 50 mil años (Svante, 2001).

Estudios publicados recientemente (Konopka et al., 2009) muestran que apenas dos mínimas diferencias (sustitución de dos aminoácidos) de un gen conocido como FOXP2 son el punto central que explica la capacidad adquirida del lenguaje en los humanos. El efecto diferenciador de ese gen desencadena una serie de cambios en el desarrollo y función cerebral que explican, entre otras cosas, nuestra capacidad para el lenguaje. Años antes, el mismo gen había sido señalado como responsable de diversos trastornos en individuos afectados que manifestaban dificultades de lenguaje, comprensión y coordinación facial, claves en la comunicación oral en humanos.

\section{Variabilidad genética humana}

A partir de la secuenciación y comparación del genoma de mayor cantidad de personas de diferentes grupos étnicos y geográficos, se ha evidenciado también la enorme complejidad de la especie humana en términos genéticos. Por una parte, queda en evidencia que las 
diferencias notables visualmente entre individuos -como el color de los ojos o de la piel, los ojos grandes o rasgados y la altura- son tan mínimas, a juzgar por el 99.99 por ciento de similitud existente entre dos personas cualesquiera, que esto debería persuadirnos de que el concepto de raza más que biológico es social.

Por otra parte, esto no significa que puedan o deban ignorarse las diferencias entre humanos. Se ha encontrado un elevado número de polimorfismos de una sola base (SNP, de su acrónimo inglés), mínimas variaciones en la secuencia de ADN. En total podrían existir alrededor de 10-12 millones de variantes de SNP en el genoma. Dada la selección natural, una diferencia genética le puede dar a un tipo de variante particular mejores oportunidades de adaptarse a un determinado medio. La aparición de la variante de color de piel clara se dio probablemente como una adaptación a las migraciones de poblaciones hacia latitudes frías del Norte. La piel oscura que bloquea mejor la luz solar en las regiones tropicales, se vuelve una desventaja en el Norte, en donde se requiere aprovechar la luz para sintetizar la vitamina $\mathrm{D}$, que es importante para el sistema óseo. La vitamina D no es tan sólo una constructora de huesos, sino que también estimula la producción de serotonina y dopamina, que juegan roles cruciales en la química del cerebro.

Además de auxiliar en la adaptación al medio, algunas variantes genéticas también pueden ser importantes para la defensa del organismo contra las enfermedades. A pesar de la enorme similitud entre humanos, el pequeñísimo porcentaje de divergencias explica nuestras diferencias con respecto a las enfermedades. Un ejemplo de esto es el polimorfismo de la enzima Citocromo P450 (CYP), una familia de proteínas que se encarga de degradar más de 30 clases de fármacos.

Cada variante del gen CYP codifica un tipo de enzima que puede presentar una reacción distinta en diferentes pacientes, lo que puede manifestarse en su eliminación eficiente o, en el caso de impedimento, su acumulación. Un tipo inactivo o poco activo de enzima no va a procesar correctamente o eliminar algún fármaco, resultando en una sobredosis. La CYP2D6 es la variante importante en el tratamiento de la depresión clínica con fármacos como la FLUOXETINA, la famosa Prozac ${ }^{2}$.

Alrededor del 40-50 por ciento de los usuarios de estos antidepresivos y anti psicóticos pueden presentar alteraciones farmacocinéticas por polimorfismos de CYP-2D6. Con estos conocimientos se puede procurar opciones de fármacos y dosis más apropiadas a las características genéticas de cada paciente.

Aunque para la mayoría de los polimorfismos no se ha descrito un efecto clínico claro, se sabe que pueden tener importancia, por ejemplo, en la predisposición a enfermedades o en cuanto a la sensibilidad a determinados fármacos (Gabriel et al., 2002). De todos estos asuntos se ocupa la fármaco-genómica, que trata de diseñar fármacos más apropiados a las variantes genéticas existentes ${ }^{3}$. Conociendo las variantes genómicas de cada paciente se estiman los niveles de riesgo/beneficio ante el fármaco, con lo cual se espera reducir las cerca de 100,000 muertes ocurridas anualmente sólo en EEUU a causa de reacciones adversas (Lazarou, Pomeranz \& Corey). 


\section{Era de la revolución ómica}

Los últimos años del siglo XX dieron paso a la más reciente 'revolución' científico-técnica que bien podría llamarse la "revolución ómica", ya que a la par de la genómica se han desarrollado la proteómica y la transcriptómica, que consideran el total de proteínas y transcriptos, respectivamente. A esto hay que agregar la carrera por secuenciar los genomas de más de cinco mil especies de microbios, plantas y animales. A lo largo de diferentes espectros filogenéticos se pueden encontrar similitudes y convergencias insospechadas.

El enorme caudal de información científico-técnica que se produce hoy día evidencia el imponente potencial creativo y transformador del quehacer científico. La aguda competencia en el área de la biotecnología, basada principalmente en la genómica y la proteómica, ha dado un gran ímpetu a la búsqueda, aislamiento, caracterización y construcción de genes. El descubrimiento de nuevos genes y proteínas es vital en la investigación biomédica porque ha llegado a constituirse como herramienta indispensable para indagar sobre la biología de los organismos y su conexión evolutiva.

Se ha abierto el camino para una nueva área del conocimiento conocida como la biología sintética, que procura la construcción de nuevos sistemas biológicos para fines industriales, como la generación de energía a partir de microorganismos. El Dr. Craig Venter, uno de los principales protagonistas del Genoma Humano, también brilla en estas nuevas tendencias. Uno de sus proyectos más fascinantes procura ayudar a reducir el efecto invernadero con microorganismos artificiales capaces de degradar los gases contaminantes y reducir la concentración de dióxido de carbono atmosférico.

\section{Perspectivas para Nicaragua}

A medida que avanza esa revolución científico-técnica también aparece en el escenario un debate desde diversos puntos de vista, en particular, del punto de vista ético y social. Surgen preguntas tales como: ¿A quién le pertenece y cómo se utilizará esa información? ¿Cuáles son las repercusiones de estos conocimientos en cuanto a patentes, propiedad intelectual, seguros e investigación criminal? ¿Quién se beneficia de este caudal de conocimientos? Estos son apenas algunos de los interrogantes. Si bien no procuro responderlos en este breve espacio -además por no considerarme experto en estos temas- es importante dejar sentado que todas estas cuestiones tienen que tratarse desde un profundo compromiso social y ético. Comparto la posición del Congreso Mundial de Bioética del $2000^{4}$ que expresa categóricamente que "el genoma humano es patrimonio de la humanidad y como tal no es patentable”.

Una pregunta inevitable es ¿̇cuáles son las posibilidades reales de que los países pobres como Nicaragua puedan beneficiarse de ese tesoro inagotable de conocimientos? En mi opinión, Nicaragua no solamente podría ser beneficiaria mediante la incorporación de tecnologías y aplicaciones, sino que también podría aportar a agrandar ese patrimonio universal.

Nicaragua cuenta ya con las bases elementales para la investigación genómica. En los últimos 10-15 años se ha venido afianzando la investigación molecular, que constituye la 
antesala de la genómica. En particular, con la creación del Centro de Biología Molecular de la Universidad Centroamericana hace ya diez años, se implantó en el país la posibilidad de la investigación molecular de interés para diferentes áreas del conocimiento.

Un caso concreto es el auxilio a la medicina forense y la investigación policial. El Centro estableció la primera base de datos de frecuencias alélicas de la población nicaragüense (Flores-Obando, Budowle \& Huete-Pérez, 2004), la cual sirve de elemento fundamental para la interpretación estadística correcta de cualquier resultado experimental. La ineludible derivación de estos trabajos es la búsqueda de marcadores moleculares de enfermedades que aquejan a la población nicaragüense. El Centro se ha propuesto también identificar marcadores específicos de los grupos étnicos nicaragüenses para comprender mejor su origen histórico-demográfico.

Un área de interés prioritario para Nicaragua es el de las enfermedades infecciosas. Hay que aprovechar que en el país existen ciertas fortalezas en el área de microbiología -principalmente médica- así como también existen algunos recursos humanos de buena calidad en el área de la informática y las tecnologías de la información. Dada esta fortaleza en informática no sería difícil crear capacidades en bioinformática, que es un requerimiento fundamental para la investigación genómica.

El Centro ha incursionado en el estudio de los genomas de parásitos de interés para Nicaragua, como el causante del mal de Chagas, el Tripanosoma cruzi (Huete-Pérez, FloresObando, Ghedin \& Caffrey, 2005). Trabajamos también en la caracterización de las variantes de cepas del parásito que circulan en nuestro país, tratando de correlacionar esto con las múltiples manifestaciones clínicas de la enfermedad (Talavera-López \& Huete-Pérez, 2008). Además, hemos realizado estudios indagando sobre la presencia de las variantes CYP-2D6, implicadas en el metabolismo de plaguicidas para determinar la susceptibilidad genética de usuarios de estos químicos (Luna-Avilés, Gminski, Mersch-Sundermann \& Huete-Pérez, 2007).

La genómica, aplicada a la biodiversidad, es un área estratégica para el desarrollo de las naciones que, como Nicaragua, cuentan con una diversidad biológica incomparable. El uso apropiado y conservacionista de la biodiversidad podría convertirse en una fuente incomparable de valor agregado para los productos agrícolas y farmacéuticos, permitiendo la identificación de nuevos genes, proteínas y procesos biotecnológicos. Esta idea la expuso claramente el Dr. Richard J. Roberts, premio Nobel de Medicina (1994), en su visita a Nicaragua en ocasión del IV Congreso Nicaragüense de Biotecnología, en 2009.

Dentro de las posibilidades para Nicaragua pueden destacarse la identificación de semillas más resistentes a plagas y sequías, mejor calidad nutricional o variedades con mejor capacidad de comercialización, microorganismos y vegetales con propiedades medicinales.

En esa misma dirección, el Centro de Biología Molecular ha incursionado en la bioprospección, procurando enzimas industriales como las endonucleasas de restricción, de uso en la industria biotecnológica (Gómez-Rodríguez \& Huete-Pérez, 2008). Gracias a una colaboración con la compañía New England Biolabs, nuestro Centro ha creado una 
base de datos microbiológica de bacterias que contienen enzimas de restricción. Un último ejemplo es el uso de la técnica conocida como DNA-Barcode (código de barras de ADN), empleado para catalogar especies cercanas de lagunas cratéricas de Nicaragua (PáizMedina \& Huete-Pérez, 2008).

La experiencia de países como Chile, Brasily México, respaldan la tesis de quela incorporación de Nicaragua a la sociedad del conocimiento no es apenas una ilusión. Un ejemplo valioso es el caso del Programa Genómico de México (Jiménez-Sánchez, 2003), que se ha convertido en el centro más importante de investigación genómica en América Latina. Con la creación del Instituto de Medicina Genómica (INMEGEN) en 2004 se estableció una estrategia basada en alianzas estratégicas de nivel nacional y con el extranjero. Además de procurar recursos externos, el gobierno destinó recursos adicionales a la estrategia de ciencia y tecnología; se destinaron esfuerzos focalizados en la mejora de los recursos humanos y se definieron las prioridades centrándose en las principales enfermedades del país. Comenzando con investigaciones sobre diabetes, obesidad, enfermedades cardiovasculares y cáncer, se ha ido implementando la fármaco-genómica y genómica de los más de 65 grupos indígenas de los que tomó origen el mexicano actual.

Una de las importantes publicaciones indica una clara diferencia de los mexicanos mestizos con respecto a los subgrupos humanos más estudiados a nivel internacional como yoruba africanos, caucásicos europeos, japoneses y chinos (Silva-Zolezzi, 2009). Dicha iniciativa, que progresa exitosamente en México, nos deja muy buenas lecciones a los países pequeños de América Central.

Al considerar estas posibilidades no debería escapar a nuestra atención subrayar el importante papel que juegan los Estados: por un lado, garantizando que con el desarrollo científico prevalezca el interés y el bienestar de la sociedad; por otro, apoyando la financiación de la ciencia, estimulando alianzas estratégicas de los centros de excelencia con los principales desarrolladores tecnológicos a nivel mundial y reforzando la institucionalidad académica y científica del país.

Para que Nicaragua pueda insertarse exitosamente en las tendencias de la economía global del conocimiento, un requisito no menos importante es preparar a la población para que pueda entender, asimilar y producir ciencia, considerada ésta en los nuevos tiempos como factor socio-cultural indispensable de la nueva generación de Homo sapiens.

\section{Notas}

1 Modificado de la ponencia del autor en la Sesión de Biomedicina del Ciclo de conferencias para la incorporación de los académicos de número de la Academia de Ciencias de Nicaragua, 16 de noviembre de 2009.

2 También la Paroxitina y otros inhibidores selectivos de la recaptación de serotonina, ISRS.

3 Sin embargo, resultados recientes de la investigación genómica apuntan también a la necesidad de métodos más sistemáticos y sensibles para lograr encontrar los genes que median la respuesta terapéutica.

4 Disponible en internet. http://www.oei.es/salactsi/bioetica.htm; http://www.sibi.org/ddc/bio.htm. 


\section{Referencias}

Flores-Obando, R. E., Budowle, B. \& Huete-Pérez, J. A. (2004) Allele frequencies for markers CSF1PO, TPOX, TH01, F13A01, FESFPS, vWA, D16S539, D7S820, D13S317 in the general population of Nicaragua. J Forensic Sci. (49), 416-417.

Gabriel, S. B., Schaffner, S. F., Nguyen, H., et al. (2002). The structure of haplotype blocks in the human genome. Science (296), 2225-2229.

Gómez-Rodríguez, J. \& Huete-Pérez, J. A. (2008). Bioprospección de enzimas de restricción en bacterias de suelos y ambientes volcánicos de Nicaragua. Encuentro. (81),70-87.

Huete-Pérez, J. A., Flores-Obando, R. E., Ghedin, E., Caffrey, C. R. (2005) Genomic and proteomic approaches for Chagas' disease: critical analysis of diagnostic methods. Expert Rev Mol Diagn. (5), 521-30.

Jiménez-Sánchez, G. (2003). Developing a platform for genomic medicine in Mexico. Science. (300), 295-296.

Konopka, G., Bomar, J. M., Winden, K., Coppola, G., Jonsson, Z. O., Gao, F., Peng, S., Preuss, T. M., Wohlschlegel, J. A. \& Geschwind, D. H. (2009). Human-specific transcriptional regulation of CNS development genes by FOXP2. Nature (462), 213-217.

Lazarou, J., Pomeranz, B. H. \& Corey, P. N. (15 de abril de 1998) Incidence of adverse drug reactions in hospitalized patients: a meta-analysis of prospective studies. JAMA. 279(15), 1200-1205.

Luna-Avilés, I., Gminski, R., Mersch-Sundermann, V. \& Huete-Pérez, J. A. (2007) Determinación de daño genético en comerciantes de plaguicidas en el departamento de Matagalpa. Encuentro (78), $76-91$.

Páiz-Medina, L. \& Huete-Pérez, J. A. (2008). DNA Barcode, una alternativa para identificar especies del Complejo Midas Cichlidae en Nicaragua. Encuentro. (81),101-113.

Silva-Zolezzi, I., Hidalgo-Miranda, A., Estrada-Gil, J., Fernandez-López, J. C., Uribe-Figueroa, L., Contreras, A., Balam-Ortiz, E., del Bosque-Plata, L., Velazquez-Fernandez, D., Lara, C., Goya, R., Hernández-Lemus, E., Dávila, C., Barrientos, E., March, S. \& JimenezSánchez, G. (2009). Analysis of genomic diversity in Mexican Mestizo populations to develop genomic medicine in Mexico. Proceedings of the National Academy of Sciences. DOI: 10.1073/pnas.0903045106.

Svante, P. (2001). Genomics and Society: The Human Genome and Our View of Ourselves. Science (291), $1219-1220$.

Talavera-López, C. N. \& Huete-Pérez, J. A. (2008) Enfermedad de Chagas: Actualidades. Encuentro (81), 88 - 98. 